\title{
Proposta de Modelo de Implementação de Escritório de Processos para Organizações Públicas
}

\section{Proposal of a BPM Center of Excellence Implementation Model for Public Organizations}

\author{
Andréia Faleiro Lautert Especialista em Business Process Management. Universidade do Vale dos Sinos (UNISINOS) - \\ Brasil. andreia.lautert@gmail.com. \\ João Francisco da Fontoura Vieira Mestre em Engenharia de Produção. Universidade Federal do Rio Grande do Sul (UFRGS) - \\ Brasil.joao.francisco@ufrgs.br \\ Arthur Marcon Mestre em Engenharia de Produção. Universidade Federal do Rio Grande do Sul (UFRGS) - \\ Brasil.arthur.marcon@ufrgs.br \\ Érico Marcon Mestre em Engenharia de Produção. Universidade Federal do Rio Grande do Sul (UFRGS) - \\ Brasil. erico.marcon@ufrgs.br
}

\begin{abstract}
RESUMO
O Escritório de Processos é o mecanismo organizacional responsável por coordenar as iniciativas de Business Process Management (BPM) nas organizações. Com vistas a consolidar o BPM, as organizações públicas vêm implementando Escritório de Processos. No entanto, este tipo de organização possui características específicas que precisam ser consideradas em um modelo de implementação de Escritório de Processos. Dado isso, o objetivo deste artigo é propor um modelo de implementação de Escritório de Processos para organizações públicas à luz das características das organizações públicas. A proposição foi aplicada em uma organização pública a fim de testar sua aplicabilidade. Reflexões a partir da aplicação foram realizadas. O modelo mostrouse viável de ser executado, no entanto ressalta-se que a burocracia, estabilidade dos funcionários, turnover da alta gestão e interesses políticos são pontos críticos que devem ser devidamente gerenciados na implementação.
\end{abstract}

Palavras-chave: Escritório de processos. BPM. Organização pública.

\begin{abstract}
The BPM Center of Excellence is responsible for coordinating Business Process Management (BPM) initiatives in organizations. In this line, public organizations have been implementing the BPM Center of Excellence to consolidate BPM. Nevertheless, public organizations have specific characteristics that need to be considered during the implementation of a BPM Center of Excellence model. The objective of this paper is to propose a model for implementing BPM Center of Excellence for public organizations that considers the characteristics of such organizations. The proposed model was applied in a public organization in order to test its efficacy. Discussions from the case were carried out. The model proved to be viable to be executed, however the bureaucracy, stability of employees, turnover of top management, and political interests are critical points that must be properly managed in the implementation.
\end{abstract}

Keywords: BPM Center of Excellence. BPM. Public Organization. 


\section{INTRODUÇÃO}

O conceito de vantagem competitiva como sendo derivado do ambiente onde as empresas estão inseridas (PORTER, 1980) é bem aderente ao setor privado, visto que seu objetivo é auferir lucro. Já, no setor público, onde o objetivo é cumprir uma função social constata-se pouca competição entre as organizações, no entanto há também a necessidade de entregar valor ao cliente final (FELIX; FELIX; TIMÓTEO, 2011). Campanário et al. (2014), ao estudar a implementação da Governança Corporativa em uma organização pública, destacou algumas características específicas deste setor que impactavam tal implementação, como: burocracia, complexidade, interesse público, conjuntura política, alternância de diretores no cargo e falta de consenso sobre os objetivos estratégicos. Também podemos acrescentar a essas características, a estabilidade e desmotivação dos empregados, a cultura organizacional, e a visão departamental (RICHARDSON, 2006). Órgãos públicos também precisam estar atentos a melhorar sua eficácia, com o objetivo de entregar serviços de qualidade à sociedade (SILVA, 2014; CAMPANÁRIO et al., 2014).

Pensando na competitividade, cada vez mais, as empresas vêm investindo em Escritório de Processos (EP) a fim de manter sua governança de processos (SCHEER; HOFFMANN, 2015; NQAMPOYl; SEYMOUR; LAAR, 2016). O EP é um mecanismo organizacional fundamental para o desenvolvimento da cultura de processos na organização, sendo o responsável por coordenar as iniciativas de Business Process Management (BPM) nas empresas (JESUS et al., 2015; PINHO et al., 2008; ELO GROUP, 2008). Como as organizações públicas estão entrando em um cenário de competição, a utilização de um EP também se faz necessária nessas instituições (ELO GROUP, 2008).

Para o sucesso da implementação do EP, precisam ser consideradas a situação organizacional e a política da instituição a fim de se alcançar os benefícios esperados (ELO GROUP, 2008; JESUS et al., 2015; ROSEMANN, 2008). A literatura traz alguns modelos de implementação de EP (e.g., TREGEAR; JESUS., 2008; USIRONO, 2015), no entanto estes possuem foco na iniciativa privada, existindo pouca literatura voltada para organizações públicas (e.g., BANDARA et al., 2018). A utilização de um modelo de implementação de EP inadequado pode levar à ineficiência do EP e desperdício de recursos.

Diante do exposto, a questão de pesquisa do presente estudo é: "Como deve ser um modelo de implementação de EPs para organizações públicas?". Dessa forma, o objetivo dessa pesquisa, é propor um modelo aderente às características do setor público. Espera-se que o produto obtido a partir da aplicação deste modelo seja um plano de ação de implementação de um EP. A proposição se baseia nos modelos já existentes na literatura e nas características dos órgãos públicos (CAMPANÁRIO et al., 2014). Dado que o foco do estudo é a construção de soluções para problemas enfrentado por empresas (DRESCH; LACERDA; ANTUNES JÚNIOR, 2015), o método utilizado foi o Design Science Research (DSR).

A estrutura do artigo está dividida em seis seções. A segunda seção contempla o referencial teórico. Já, na terceira seção, são apresentados os procedimentos metodológicos do estudo. Na quarta seção, é apresentado o artefato proposto e são descritos os resultados de sua aplicação. Na quinta seção, os resultados obtidos são discutidos. Por fim, as conclusões, limitações do estudo e proposições de trabalhos futuros são apresentados na sexta seção.

\section{FUNDAMENTAÇÃO TEÓRICA}

Nesta seção, a fim de dar suporte ao entendimento do artigo e apresentar os principais resultados já obtidos na literatura correlata ao tema, é apresentada uma revisão teórica dos assuntos: (i) Escritório de processos e modelos de implementação, (ii) BPM e EPs em organizações públicas.

\subsection{Escritório de processos e modelos de implementação}

O EP tem sido amplamente adotado por empresas que aderem ao BPM, uma vez que é o responsável pelo alinhamento das estratégias com os processos (JESUS et al., 2015; SCHEER; HOFFMANN, 2015; TREGEAR; JESUS., 2008; DYER et al., 2013). Conforme Paim, Mansur Caulliraux e Cardoso (2008), os benefícios da adoção de um EP por uma empresa são o aprimoramento organizacional, visão holística dos processos, e desempenho 
integrado e coordenado das atividades. Dentre os serviços oferecidos pelo EP à organização, destacam-se: alinhamento estratégico, modelagem de processos, melhoria do processo, conformidade do processo, e medição do desempenho do processo (ROSEMANN, 2008; JESUS et al., 2009; ELO GROUP, 2008). Assim, o EP proporciona metodologia, cultura, educação, e práticas para se atingir os objetivos com boa relação custobenefício (TREGEAR; JESUS., 2008).

De acordo com Usirono (2015), existem três tipos de estrutura de EP: centralizado, descentralizado ou híbrido. Essa classificação existe para atender, de forma estratégica, a governança de processos, considerando a estrutura de negócios da organização. No modelo centralizado, o EP, com os colaboradores concentrados fisicamente em um único local, estabelece a padronização e disseminação dos métodos, técnicas e ferramentas que as unidades de negócio irão utilizar. Já, no modelo descentralizado, cada unidade de negócio, padroniza a sua governança. Por fim, no modelo híbrido, apesar das unidades de negócios possuírem seus próprios analistas, esses se reportam funcionalmente ao EP central.

A implementação de um EP requer planejamento adequado para que se obtenha os benefícios esperados. Dessa forma, estabelecer um modelo de implementação é fundamental para seu sucesso (ELO GROUP, 2008; RICHARDSON, 2006). Diversos modelos de implementação de EP já foram propostos (ELO GROUP, 2008; RICHARDSON, 2006). Ressalta-se que, para o sucesso da implementação, os modelos precisam ser devidamente estudados e adaptados à realidade da organização (RICHARDSON, 2006).

Não há unanimidade sobre qual o modelo mais adequado para a implementação de EPs (PAIM; MANSUR CAULLIRAUX; CARDOSO, 2008; RICHARDSON, 2006). Os modelos possuem passos distintos entre si, visando atender a diversas circunstâncias. Observa-se que os modelos sugeridos por ELO GROUP (2008), Tregear e Jesus (2008) e Jesus et al. (2015), possuem etapas voltadas para a gestão estratégica; enquanto os modelos propostos por Usirono (2015) e Pinho et al. (2008) focam na operação do EP.

A Figura 1 apresenta uma comparação dos modelos para implementação de EPs propostos pela literatura e uma compilação destes, denominada de modelo-base, que visa a ser um ponto de convergência entre as propostas. $O$ modelo-base é composto por etapas que aparecem em, pelo menos, um dos modelos revisados, contemplando, portanto, o foco gerencial e operacional para a implementação do EP. 
Figura 1 - Comparação dos Modelos de Implementação de EPs

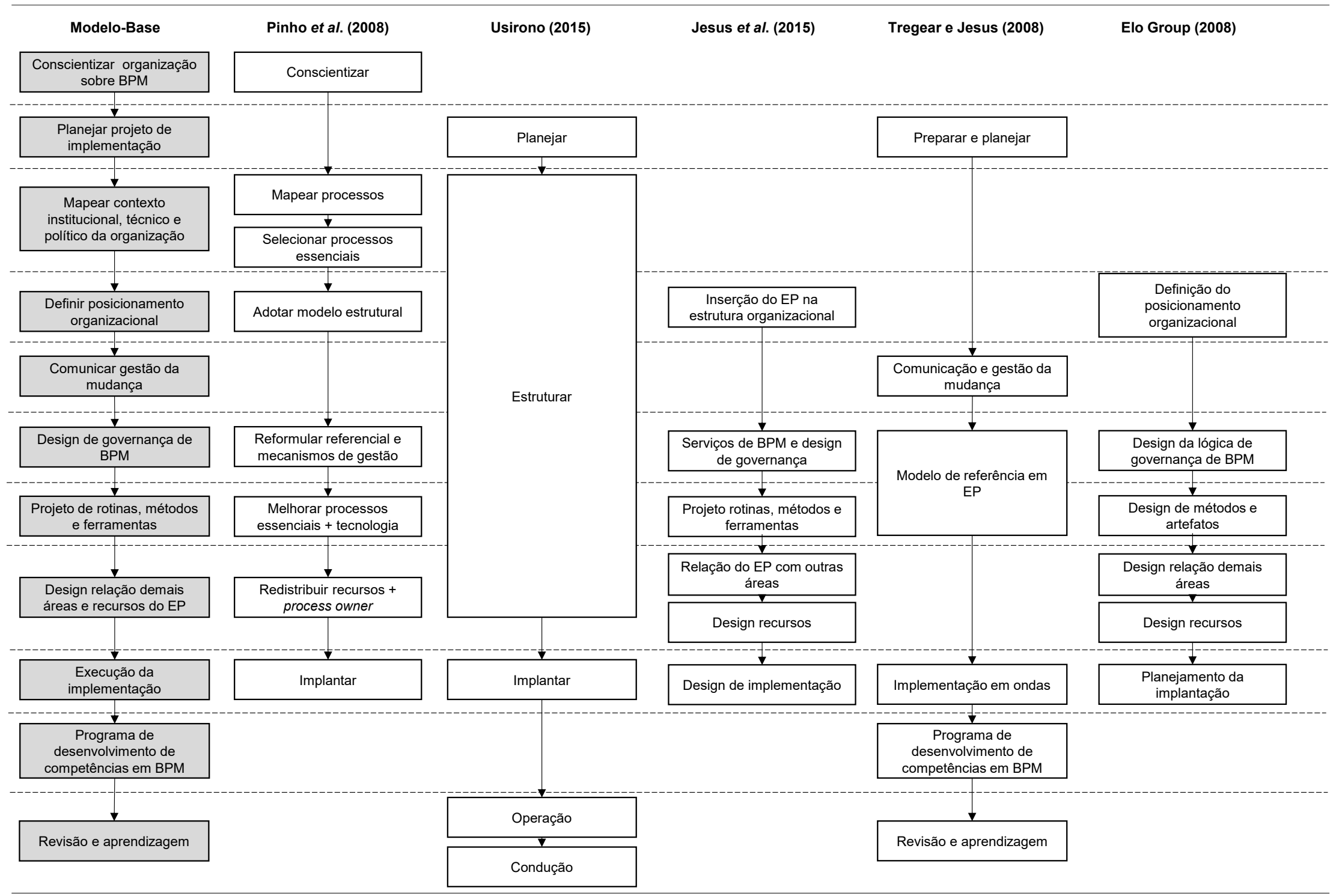

Elaborado pelos Autores (2020). 
No Quadro 1, são apresentadas e descritas as onze etapas que compõem o modelo-base. As cinco primeiras etapas focam principalmente em conscientizar sobre o BPM e a importância do EP, comunicar a organização sobre a mudança, e planejar a implementação do EP. Já, as etapas seis, sete, e oito se referem ao design e estruturação do EP. A etapa nove é onde o EP é, de fato, implementado, considerando as definições das etapas anteriores. Na etapa dez, são desenvolvidas as competências em BPM dos funcionários da empresa. Por fim, a etapa onze serve ao propósito de revisar a implementação sob a ótica da melhoria contínua, englobando os aprendizados das etapas anteriores.

Quadro 1 - Etapas do modelo-base

\begin{tabular}{|c|c|}
\hline Etapa & Descrição \\
\hline $\begin{array}{l}\text { 1- Conscientizar a organização } \\
\text { sobre BPM }\end{array}$ & $\begin{array}{l}\text { Conscientizar a organização sobre os benefícios da } \\
\text { implementação do BPM e informar o papel de cada colaborador } \\
\text { no processo }\end{array}$ \\
\hline $\begin{array}{l}2 \text { - Planejar o projeto de } \\
\text { implementação }\end{array}$ & $\begin{array}{l}\text { Planejamento do projeto, com definição da equipe, objetivo e } \\
\text { cronograma de implementação }\end{array}$ \\
\hline $\begin{array}{l}3 \text { - Mapear o contexto da } \\
\text { organização }\end{array}$ & $\begin{array}{l}\text { Análise do contexto institucional, técnico e político do ambiente } \\
\text { onde será implementado o EP, identificando-se Forças, } \\
\text { Oportunidades, Fraquezas e Ameaças da organização }\end{array}$ \\
\hline $\begin{array}{l}4 \text { - Definir o posicionamento } \\
\text { organizacional do EP }\end{array}$ & $\begin{array}{l}\text { Definição da posição do EP na estrutura organizacional em } \\
\text { função do nível de maturidade da organização em BPM }\end{array}$ \\
\hline $\begin{array}{l}5 \text { - Comunicar a gestão da } \\
\text { mudança }\end{array}$ & $\begin{array}{l}\text { Criação do canal de comunicação sobre a gestão da mudança, } \\
\text { visando informar às partes interessadas sobre o andamento e } \\
\text { resultado do processo de implementação }\end{array}$ \\
\hline 6 - Design de governança de BPM & $\begin{array}{l}\text { Definição dos serviços prestado pelo EP, responsabilidades } \\
\text { relacionadas a cada serviço e garantia de que as iniciativas em } \\
\text { BPM estejam colaborando para o alcance dos objetivos } \\
\text { estratégicos da organização }\end{array}$ \\
\hline $\begin{array}{l}7 \text { - Projeto de rotinas, métodos e } \\
\text { ferramentas internas do EP }\end{array}$ & $\begin{array}{l}\text { Definição da metodologia do trabalho interno do EP, das } \\
\text { ferramentas, fluxos, técnicas e modelos que serão utilizados }\end{array}$ \\
\hline $\begin{array}{l}8 \text { - Design de relação com demais } \\
\text { áreas e recursos do EP }\end{array}$ & $\begin{array}{l}\text { Definição da relação do EP com as demais áreas de negócio da } \\
\text { organização, considerando os serviços que serão prestados. } \\
\text { Definição do orçamento, recursos humanos e tecnológicos que o } \\
\text { EP irá utilizar }\end{array}$ \\
\hline 9 - Execução da implementação & $\begin{array}{l}\text { Definição e execução da estratégia para implementar o que foi } \\
\text { definido até então. }\end{array}$ \\
\hline $\begin{array}{l}10 \text { - Programa de } \\
\text { desenvolvimento de } \\
\text { competências em BPM }\end{array}$ & $\begin{array}{l}\text { Desenvolvimento da capacidade interna dos colaboradores em } \\
\text { BPM }\end{array}$ \\
\hline 11 - Revisão e aprendizagem & Definição da metodologia de melhoria contínua dos processos \\
\hline
\end{tabular}

Elaborado pelos Autores (2020).

\subsection{BPM e EPs em organizações públicas}

O principal objetivo das organizações públicas é atender a alguma demanda da sociedade. Portanto, seu principal cliente é o cidadão, que requer atendimento com transparência, integridade e eficiência (TREGEAR; JESUS., 2008; GESPÚBLICA, 2010).

As organizações públicas possuem características em comum, como por exemplo: burocracia, ausência de dados para tomada de decisão, complexidade, processos sem padronização, turnover da alta gestão, ausência de processos estratégicos, regras de negócios sem clareza, interesses políticos, quadro funcional com estabilidade, e mecanismo insuficiente para gestão de desempenho (CAMPANÁRIO et al., 2014; SILVA, 2014). Essas características geram falta de consenso sobre os objetivos da governança corporativa, afetando as relações institucionais, o ambiente e a estrutura organizacional (BOYNE, 2002). 
Acredita-se que a adoção do BPM em organizações públicas pode contribuir para que sejam supridas as necessidades da sociedade com maior qualidade, agilidade e eficácia (SILVA, 2014; OLIVEIRA, 2014; BANDARA et al., 2018). No entanto, considerando que as especificidades das empresas influenciam no grau de maturidade em BPM em que esta se encontra (BOER, 2014), é possível afirmar que as organizações públicas estão em um nível de maturidade baixo na implementação de um BPM. Sendo assim, para Silva (2014), apesar de o BPM poder ser implantado tanto em empresas privadas quanto públicas, isto tem se mostrado mais desafiador nas organizações públicas. No Quadro 2, são apresentadas as características que dificultam o bom desempenho das organizações públicas e como o BPM contribuí para saná-las baseado em Silva (2014) e Campanário et al. (2014).

Geralmente, vislumbram-se iniciativas de BPM em uma organização pública quando há a implementação de um Enterprise Resource Planning (ERP), pois há percepção de que o redesenho dos processos é o caminho para otimização dos custos e melhoria da interface entre as áreas de negócios existentes na organização (JESUS et al., 2015, PINHO et al., 2008). Portanto, este pode ser considerado um primeiro passo para a inserção da cultura de BPM neste tipo de organização. No entanto, para que essas iniciativas sejam absorvidas pela alta gestão e corpo funcional, dado que há resistência à mudança, a comunicação do que está acontecendo na organização é extremamente importante. É de fundamental importância o foco na comunicação, se não o BPM pode estar fadado ao fracasso (JESUS et al., 2015, PINHO et al., 2008).

Quadro 2 - Características organizações públicas e possíveis contribuições do BPM

\begin{tabular}{|c|c|}
\hline Características das Organizações Públicas & Contribuições do BPM \\
\hline $\begin{array}{l}\text { Burocracia: Atividades em excesso, burocratizando } \\
\text { os processos }\end{array}$ & $\begin{array}{l}\text { Racionalização das atividades visando redução da } \\
\text { burocracia }\end{array}$ \\
\hline $\begin{array}{l}\text { Interesse político: Processos/atividades criadas } \\
\text { e/ou alteradas para satisfazer interesse político }\end{array}$ & $\begin{array}{l}\text { Foco na cadeia de valor da organização para } \\
\text { minimizar as constantes alterações ou criações de } \\
\text { novos processos }\end{array}$ \\
\hline $\begin{array}{l}\text { Complexidade: Muitos regramentos internos e } \\
\text { externos a serem seguidos, tornando os processos e } \\
\text { atividades complexos }\end{array}$ & $\begin{array}{l}\text { A adoção da melhoria contínua dos processos faz } \\
\text { com que normativos internos que não agregam } \\
\text { valor sejam extintos ou alterados }\end{array}$ \\
\hline $\begin{array}{l}\text { Quadro funcional estável: Colaboradores não } \\
\text { engajados no projeto de implementação BPM }\end{array}$ & $\begin{array}{l}\text { Faz o colaborador sentir-se como parte primordial } \\
\text { para o sucesso do projeto }\end{array}$ \\
\hline $\begin{array}{l}\text { Turnover alta gestão: Risco de ter o processo } \\
\text { interrompido se iniciado ou estiver iniciando em } \\
\text { uma virada de gestão }\end{array}$ & $\begin{array}{l}\text { Mantém as novas gestões alinhadas às inciativas de } \\
\text { os projetos existentes }\end{array}$ \\
\hline $\begin{array}{l}\text { Ausência de processos estratégicos: Risco de não } \\
\text { ter uma direção de para onde a empresa pretende } \\
\text { estar no futuro }\end{array}$ & Adoção de ações baseadas no contexto \\
\hline $\begin{array}{l}\text { Processos sem padronização: Processos } \\
\text { executados sem um padrão, sendo este afetado } \\
\text { pelas particularidades do funcionário que o está } \\
\text { executando }\end{array}$ & Padronização da organização com visão no cliente \\
\hline $\begin{array}{l}\text { Regras de negócios sem clareza: Risco de replicar } \\
\text { erroneamente os processos existentes }\end{array}$ & $\begin{array}{l}\text { Adequação das regras de negócio, objetivando dar } \\
\text { transparência aos processos e atividades }\end{array}$ \\
\hline
\end{tabular}

Fonte: Adaptado de Silva (2014) e Campanário et al. (2014).

\section{PROCEDIMENTOS METODOLÓGICOS}

Considerando que o trabalho tem por objetivo resolver um problema de ordem prática, o método de pesquisa utilizado foi o Design Science Research (DSR), o qual visa reduzir o intervalo entre a teoria e a prática (HEVNER; MARCH; PARK., 2004; HOMLSTRÖM; KETOKIVI; HAMERI, 2009). O DSR tem por objetivo criar mecanismos que visam à solução de problemas, a partir de seu entendimento, gerando circunstâncias melhores ou desejáveis (DRESCH et al., 2015. Conforme Dresch, Lacerda e Antunes Júnior (2015), o estudo 
gerado através da DSR deve ser generalizado para uma classe de problemas, dessa forma, seus resultados poderão ser analisados e utilizados por outros profissionais e pesquisadores. As etapas da pesquisa estão apresentadas no Quadro 3.

Quadro 3 - Etapas da Pesquisa

\begin{tabular}{|c|c|}
\hline Etapa & Descrição \\
\hline Proposição do Artefato & $\begin{array}{c}\text { Proposição de um modelo para a implementação de EPs em organizações } \\
\text { públicas a partir do cruzamento do modelo-base para implementação de EPs } \\
\text { (apresentado na subseção 2.1) com as características das organizações } \\
\text { públicas. (apresentadas na subseção 2.2) }\end{array}$ \\
\hline Aplicação do Artefato & $\begin{array}{c}\text { Aplicação do artefato em uma organização pública, mais especificamente } \\
\text { uma companhia de saneamento, controlada por órgão público, localizada na } \\
\text { região sul do Brasil }\end{array}$ \\
\hline Avaliação da Aplicação & Avaliação do plano de ação, gerado a partir da aplicação do artefato, juntos \\
aos gestores da organização
\end{tabular}

Elaborado pelos Autores (2020).

A proposição do artefato consistiu na construção de um modelo de implementação de EP para organizações públicas, o qual foi obtido a partir do cruzamento das etapas do modelo-base com as características das organizações públicas. $O$ artefato proposto é apresentado no Quadro 4 da seção 4. Após a proposição, na DSR, o artefato é aplicado. Ressalta-se que o resultado esperado a partir da aplicação do artefato é um plano contendo ações necessárias para a implementação de um EP em uma organização pública.

Assim, a aplicação do artefato foi realizada em uma companhia de saneamento, controlada por órgão público, localizada na região sul do Brasil, a qual tem o objetivo de explorar os serviços de água potável e esgotamento sanitário. A empresa é considerada braço estratégico do governo na execução das políticas públicas de saneamento básico. No presente trabalho, a empresa será denominada de "Empresa A". Para aplicar o artefato, foram realizadas reuniões de alinhamento com um grupo de gestores, composto por um engenheiro, dois administradores, um contador e um analista de sistemas, todos com mais de dez anos de experiência na companhia e com vasto conhecimento dos processos e do planejamento estratégico da organização. A dinâmica da aplicação consistiu na apresentação de cada etapa aos participantes, seus pontos críticos e diretrizes para superá-los. A partir daí, foram realizadas discussões para definir as ações resultantes em cada etapa. Ao final, todas as ações foram compiladas em um plano de ação único.

De posse do resultado do artefato (i.e., do plano de ação para implementação), a fim de avaliar se os objetivos esperados foram alcançados, foi realizada uma reunião individual com cada um dos participantes e uma reunião geral com a participação de todos com o objetivo de coletar suas impressões sobre o plano de ação proposto.

\section{RESULTADOS}

Nesta seção, são apresentados os resultados das três etapas do método: (i) proposição do artefato, (ii) aplicação do artefato e (iii) avaliação da aplicação.

\subsection{Proposição do artefato}

Inicialmente, foi identificado como as características das organizações públicas impactam as etapas do modelo-base (Quadro 4). Todas as relações apresentadas devem ser interpretadas como pontos críticos na execução das etapas em função das características relacionadas. $O$ quadro deve ser analisado das colunas para as linhas. 
Quadro 4 - Cruzamento das características de organizações públicas com o modelo-base

\begin{tabular}{|c|c|c|c|c|c|c|c|c|}
\hline & Burocracia & Interesse político & Complexidade & $\begin{array}{l}\text { Quadro funcional } \\
\text { estável }\end{array}$ & Turnover alta gestão & $\begin{array}{l}\text { Ausência de } \\
\text { processos } \\
\text { estratégicos }\end{array}$ & $\begin{array}{l}\text { Processos sem } \\
\text { padronização }\end{array}$ & $\begin{array}{l}\text { Regras de negócios } \\
\text { sem clareza }\end{array}$ \\
\hline $\begin{array}{r}\text { Conscientizar a organização } \\
\text { sobre BPM }\end{array}$ & & & & $\begin{array}{c}\text { Exige conscientização } \\
\text { assertiva }\end{array}$ & & & & \\
\hline $\begin{array}{r}\begin{array}{r}\text { Planejar o projeto de } \\
\text { implementação }\end{array} \\
\end{array}$ & $\begin{array}{l}\text { Introduz etapas que } \\
\text { não agregam valor }\end{array}$ & & & $\begin{array}{l}\text { Dificulta a atribuição } \\
\text { de responsabilidades }\end{array}$ & & & & \\
\hline $\begin{array}{r}\text { Mapear o contexto da } \\
\text { organizaçẫo }\end{array}$ & & & $\begin{array}{l}\text { Dificulta o } \\
\text { entendimento do } \\
\text { contexto }\end{array}$ & & & $\begin{array}{c}\text { Dificulta o } \\
\text { entendimento da } \\
\text { função da empresa }\end{array}$ & & \\
\hline $\begin{array}{r}\text { Definir o posicionamento } \\
\text { organizacional do EP }\end{array}$ & & $\begin{array}{c}\text { Acentua a disputa por } \\
\text { qual área irá abrigar o } \\
\text { EP }\end{array}$ & $\begin{array}{l}\text { Pode limitar a } \\
\text { autonomia do EP }\end{array}$ & & $\begin{array}{l}\text { Pode alterar acordos } \\
\text { sobre posição } \\
\text { organizacional }\end{array}$ & $\begin{array}{c}\text { Dificulta } \\
\text { entendimento da } \\
\text { função estratégica do } \\
\text { EP }\end{array}$ & & \\
\hline $\begin{array}{r}\text { Comunicar a gestão da } \\
\text { mudança }\end{array}$ & $\begin{array}{l}\text { Retarda o processo } \\
\text { de comunicação }\end{array}$ & & & $\begin{array}{c}\text { Exige uma } \\
\text { comunicação } \\
\text { assertiva para a } \\
\text { mudança }\end{array}$ & $\begin{array}{c}\text { Pode gerar diferentes } \\
\text { entendimentos para } \\
\text { o projeto }\end{array}$ & & & \\
\hline $\begin{array}{r}\text { Design de governança de } \\
\text { BPM }\end{array}$ & $\begin{array}{l}\text { Representa entraves à } \\
\text { execução da } \\
\text { governança }\end{array}$ & & $\begin{array}{l}\text { Dificulta a } \\
\text { governança devido } \\
\text { ao excesso de } \\
\text { instâncias }\end{array}$ & & & $\begin{array}{l}\text { Gera indefinição do } \\
\text { papel do EP na } \\
\text { governança }\end{array}$ & $\begin{array}{l}\text { Dificulta a execução } \\
\text { os controles } \\
\text { necessários }\end{array}$ & $\begin{array}{l}\text { Dificulta a definição } \\
\text { das funções do EP na } \\
\text { organização }\end{array}$ \\
\hline $\begin{array}{r}\text { Projeto de rotinas, métodose } \\
\text { ferramentas internas do EP } \\
\end{array}$ & $\begin{array}{l}\text { Representa entraves à } \\
\text { gestão interna do EP } \\
\end{array}$ & & & & & & & \\
\hline $\begin{array}{r}\text { Design da relação com } \\
\text { demais áreas e recursos do } \\
\text { EP }\end{array}$ & $\begin{array}{c}\text { Dificulta a } \\
\text { comunicação com as } \\
\text { demais áreas }\end{array}$ & $\begin{array}{c}\text { Pode trazer vieses } \\
\text { políticos nos acordos } \\
\text { firmados }\end{array}$ & & & & & & \\
\hline Execução da implementação & $\begin{array}{l}\text { Ameaça o prazo de } \\
\text { implementação }\end{array}$ & & & $\begin{array}{l}\text { Dificulta o } \\
\text { engajamento na } \\
\text { implementação }\end{array}$ & & & & \\
\hline $\begin{array}{r}\text { Programa de } \\
\text { desenvolvimento de } \\
\text { competências em BPM }\end{array}$ & & & & $\begin{array}{c}\text { Gera desinteresse nas } \\
\text { capacitações } \\
\text { necessárias } \\
\end{array}$ & & & & \\
\hline Revisão e aprendizagem & & $\begin{array}{l}\text { Pode tirar o foco da } \\
\text { melhoria contínua }\end{array}$ & & $\begin{array}{c}\text { Gera desinteresse na } \\
\text { sequência aos } \\
\text { trabalhos }\end{array}$ & & & & \\
\hline
\end{tabular}

Elaborado pelos Autores (2020). 
Baseado nesta análise, foi elaborado um modelo de implementação com foco em organizações públicas. O modelo proposto contém dez etapas: realizar sensibilização em BPM; criar o projeto de implementação do EP; mapear o contexto da organização; definir o posicionamento organizacional do EP; criar canal de gestão da mudança; criar cartilha de governança em BPM; projetar recursos, rotinas, métodos e ferramentas do EP; realizar capacitação em BPM; planejar execução da implementação e criar comitê de desempenho e melhoria contínua. O modelo proposto (Quadro 5) contempla, em cada etapa, os pontos críticos/características que impactam a implementação do EP em uma organização públicas. Dessa forma, para cada etapa estão elencadas as ações que devem ser observadas para superar estes pontos críticos. 
Quadro 5 - Artefato proposto

\begin{tabular}{|c|c|c|c|}
\hline Etapa & Descrição & $\begin{array}{c}\begin{array}{c}\text { Pontos críticos da } \\
\text { etapa }\end{array} \\
\end{array}$ & Ação para superar os pontos críticos \\
\hline $\begin{array}{l}1 \text { - Realizar } \\
\text { sensibilização em } \\
\text { BPM }\end{array}$ & $\begin{array}{l}\text { Sensibilização do corpo funcional e gestores sobre } \\
\text { os benefícios da implementação do BPM, focando } \\
\text { na entrega de valor ao cliente, e demonstração da } \\
\text { importância de cada colaborador no processo. }\end{array}$ & $\begin{array}{l}\text { - Estabilidade } \\
\text { dos } \\
\text { empregados }\end{array}$ & $\begin{array}{l}\text { Fazer os funcionários se sentirem importantes no processo, } \\
\text { engajando-os para facilitar a introdução do BPM a partir de } \\
\text { cursos, workshops e concursos internos. }\end{array}$ \\
\hline $\begin{array}{l}2 \text { - Criar o projeto } \\
\text { de } \\
\text { implementação } \\
\text { do EP }\end{array}$ & $\begin{array}{l}\text { Planejamento do projeto, com definição do } \\
\text { sponsor, equipe, objetivo, orçamento, entregáveis } \\
\text { e cronograma de implementação. }\end{array}$ & $\begin{array}{l}\text { - } \quad \text { Burocracia; } \\
\text { Turnoverda } \\
\text { alta gestão }\end{array}$ & $\begin{array}{l}\text { Criar o projeto, preferencialmente, no primeiro ano da gestão, } \\
\text { para evitar o seu cancelamento quando houver troca de } \\
\text { gestão. Além disso, recomenda-se que o projeto seja } \\
\text { finalizado durante a gestão vigente. }\end{array}$ \\
\hline $\begin{array}{l}3 \text { - Mapear o } \\
\text { contexto da } \\
\text { organização }\end{array}$ & $\begin{array}{l}\text { Análise dos objetivos estratégicos e cadeia de } \\
\text { valor da companhia, bem como, o contexto } \\
\text { político para novos projetos na qual a organização } \\
\text { está inserida. }\end{array}$ & $\begin{array}{l}\text { - } \text { Complexidade; } \\
\text { - Ausência de } \\
\text { visão } \\
\text { estratégica } \\
\end{array}$ & $\begin{array}{l}\text { Focar nos objetivos estratégicos da companhia e simplificar } \\
\text { os processos, sempre visando gerar valor para a sociedade. } \\
\text { Engajar os funcionários com sua participação na formação } \\
\text { dos objetivos. }\end{array}$ \\
\hline $\begin{array}{l}4 \text { - Definir o } \\
\text { posicionamento } \\
\text { organizacional } \\
\text { do EP }\end{array}$ & $\begin{array}{l}\text { Definição de onde ficará localizado o EP na } \\
\text { estrutura organizacional e análise do nível de } \\
\text { maturidade da organização em BPM. }\end{array}$ & $\begin{array}{l}\text { - Interesse } \\
\text { político; } \\
\text { - Complexidade; } \\
\text { - Turnoverda } \\
\text { alta gestão; } \\
\text { - Ausência de } \\
\text { visão } \\
\text { estratégica } \\
\end{array}$ & $\begin{array}{l}\text { Localizar o EP, preferencialmente no órgão mais alto da } \\
\text { estrutura hierárquica, a fim de que este tenha autonomia para } \\
\text { fazer as mudanças necessárias sem que haja interferência/ } \\
\text { descontinuidade em suas funções em prol de políticas } \\
\text { internas e externas. }\end{array}$ \\
\hline $\begin{array}{l}5 \text { - Criar canal de } \\
\text { gestão da } \\
\text { mudança }\end{array}$ & $\begin{array}{l}\text { Criação do canal de comunicação sobre a gestão } \\
\text { da mudança, visando possibilitar as partes } \\
\text { interessadas sobre o andamento, melhorias } \\
\text { esperadas e resultado do processo de } \\
\text { implementação. }\end{array}$ & $\begin{array}{l}\text { - } \text { Burocracia; } \\
\text { Estabilidade } \\
\text { dos } \\
\text { empregados; } \\
\text { Turnoverda } \\
\text { alta gestão }\end{array}$ & $\begin{array}{l}\text { A partir do aprendizado em BPM, trazer a colaboração do } \\
\text { corpo funcional na formação/alteração dos processos, com } \\
\text { foco no interesse público da organização. }\end{array}$ \\
\hline $\begin{array}{l}6 \text { - Criar cartilha } \\
\text { de governança } \\
\text { em BPM }\end{array}$ & $\begin{array}{l}\text { Definição do tipo de estrutura do EP, dos serviços } \\
\text { que serão oferecidos, delimitação da área de } \\
\text { atuação, relação com demais áreas de negócio da } \\
\text { companhia e garantia que as iniciativas em BPM } \\
\text { estejam corroborando com os objetivos } \\
\text { estratégicos. }\end{array}$ & $\begin{array}{l}\text { - } \text { Burocracia; } \\
\text { - Complexidade; } \\
\text { - Ausência de } \\
\text { visão } \\
\text { estratégica; } \\
\text { - Falta de } \\
\text { padronização; }\end{array}$ & $\begin{array}{l}\text { Estruturar a governança para simplificar a entrega de valor } \\
\text { para a sociedade, reduzindo-se burocracia nos serviços } \\
\text { prestados. }\end{array}$ \\
\hline
\end{tabular}




\begin{tabular}{|c|c|c|c|}
\hline & & $\begin{array}{l}\text { - Regras de } \\
\text { Negócio sem } \\
\text { Clareza }\end{array}$ & \\
\hline $\begin{array}{l}7 \text { - Projetar } \\
\text { recursos, rotinas, } \\
\text { métodos e } \\
\text { ferramentas do } \\
\text { EP }\end{array}$ & $\begin{array}{l}\text { Definição dos recursos humanos, tecnológicos, } \\
\text { orçamento, padrões, rotinas, ferramentas, } \\
\text { métodos, técnicas e modelos que serão utilizados } \\
\text { pelo EP. }\end{array}$ & $\begin{array}{l}\text { - Burocracia; } \\
\text { - Complexidade }\end{array}$ & $\begin{array}{l}\text { Agilizar a implementação do EP através das definições dos } \\
\text { recursos necessários. Projetar simplicidade nas rotinas de } \\
\text { trabalho, facilitando a relação entre os departamentos nos } \\
\text { processos da organização. }\end{array}$ \\
\hline $\begin{array}{l}8 \text { - Realizar } \\
\text { capacitação em } \\
\text { BPM }\end{array}$ & $\begin{array}{l}\text { Capacitação interna para implementação do EP e } \\
\text { cursos permanentes em gestão de processos. }\end{array}$ & $\begin{array}{l}\text { - Estabilidade } \\
\text { dos } \\
\text { empregados }\end{array}$ & $\begin{array}{l}\text { Engajar os empregados no BPM, através de cursos } \\
\text { permanentes sobre o assunto, fazendo-os se sentir } \\
\text { importantes e necessários para a organização. }\end{array}$ \\
\hline $\begin{array}{l}9 \text { - Planejar } \\
\text { execução da } \\
\text { implementação }\end{array}$ & $\begin{array}{l}\text { Definição da estratégia e etapas da } \\
\text { implementação do EP. }\end{array}$ & $\begin{array}{l}\text { - Estabilidade } \\
\text { dos } \\
\text { empregados; } \\
\text { - Burocracia; }\end{array}$ & $\begin{array}{l}\text { Planejar a execução da implementação de forma a simplificar } \\
\text { os processos. Escolher se a implementação será executada de } \\
\text { uma só vez ou será executada "em ondas". }\end{array}$ \\
\hline $\begin{array}{l}10 \text { - Criar comitê } \\
\text { de desempenho } \\
\text { e melhoria } \\
\text { contínua }\end{array}$ & $\begin{array}{l}\text { Definição de um comitê responsável por definir as } \\
\text { métricas, KPIs e metas para acompanhamento do } \\
\text { desempenho dos processos e melhoria contínua. }\end{array}$ & $\begin{array}{l}\text { - Interesse } \\
\text { político; } \\
\text { - Estabilidade } \\
\text { dos } \\
\text { empregados; }\end{array}$ & $\begin{array}{l}\text { Criar o comitê e responsabilizá-lo pela estruturação de } \\
\text { reuniōes de acompanhamentos e discussões dos resultados } \\
\text { obtidos nos projetos de melhoria de processos. }\end{array}$ \\
\hline
\end{tabular}

Elaborado pelos Autores (2020) 


\subsection{Aplicação do Artefato na "Empresa A"}

Conforme apresentado na seção 3, para a aplicação do artefato na "Empresa A", foram realizadas reuniões para a definição de um plano de ação para a implementação de um EP na organização. Para a definição das ações a serem realizadas em cada etapa, o grupo observava a descrição da etapa, bem como seus pontos críticos e as diretrizes para superá-los. Permitiu-se que todos pudessem se manifestar sobre a ação a ser realizada. Ao final, as ações escolhidas eram validadas por todo o grupo. O plano de ação construído está apresentado no Quadro 6.

Quadro 6 - Plano de Ação para Implementação do EP para a "Empresa A"

\section{1 - Realizar sensibilização em BPM}

- Realização de workshops nas diretorias e gerentes de todas as unidades, tendo como público-alvo diretores, gestores, assessores e assistentes com o objetivo de buscar apoio ao projeto;

- Realização de mini workshops para os funcionários operacionais a fim de explicar a ação que estava sendo desenvolvida;

- Criação de um conteúdo EAD no portal da Universidade Corporativa sobre o que é o BPM, a função do EP, seus benefícios e importância.

\section{2 - Criar projeto de implementação do EP}

- Criação do projeto e definição do sponsor. Obs: espera-se que o sponsor seja o presidente da companhia a fim de mitigar quaisquer problemas relacionados a tensões políticas dentro da organização;

- Definição do gerente do projeto, que deve ser, preferencialmente, um colaborador de carreira, que tenha, no mínimo, 10 anos de trabalho na organização, com experiência como gestor e vasto conhecimento dos processos;

- Definição do escopo e objetivo do projeto, o qual deve estar focado na melhoria da geração de valor à sociedade com a implementação do EP;

- Definição dos entregáveis do projeto e prazos, os quais devem ser executados durante o período de vigência da atual gestão (o qual, geralmente, é o mesmo período do governador do estado);

- Definição do orçamento do projeto, o qual deve respeitar a lei orçamentária (definido pelo governador do estado e assembleia legislativa);

- Definição da equipe de implementação do projeto e a qual se espera que irá compor o EP;

- Realização de entrevistas com os possíveis membros a fim de avaliar o grau de conhecimento em BPM e dos processos da organização;

- Realização de licitação e contratação de consultoria para auxiliar no processo de implementação.

\section{3 - Mapear contexto da organização}

- Identificação dos objetivos estratégicos da companhia que tem relação com o projeto de implementação do EP;

- Mapeamento da cadeia de valor da empresa;

- Identificação do contexto político atual e como este impacta o projeto.

\section{4 - Definir posicionamento organizacional do EP}

- Criação de um setor de assessoria à presidência, onde o EP deve estar posicionado.

\section{5 - Criar canal da gestão da mudança}

- Solicitação que a consultoria realize um diagnóstico nas diretorias e áreas de negócio para avaliar o nível de maturidade em BPM na organização;

- Criação de slogan para o projeto;

- Encaminhamento semanal de e-mail para toda a organização sobre a importância, benefícios e valorização dos colaboradores no processo de implementação do BPM; 


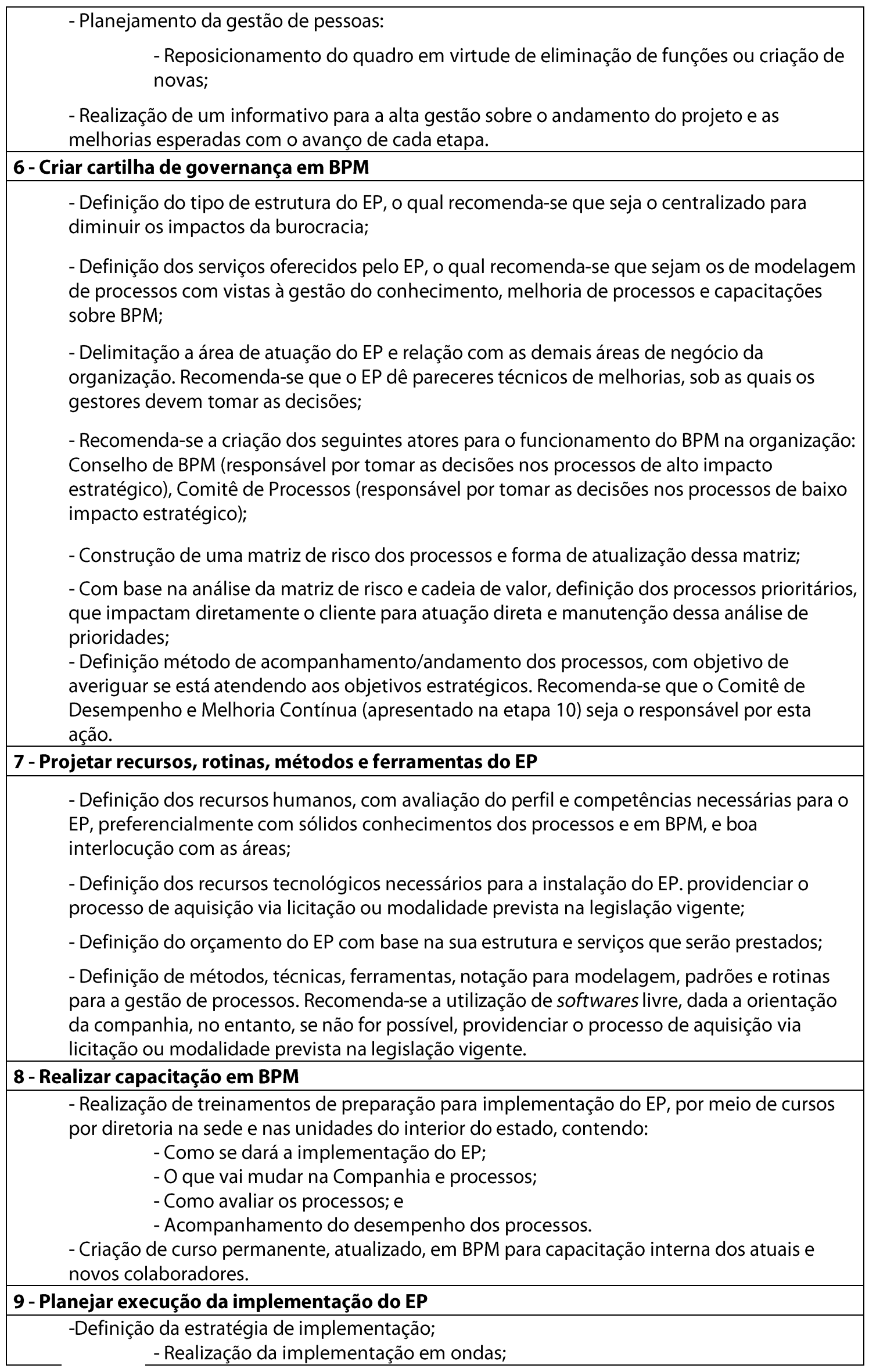


- Com base na análise da matriz de risco e cadeia de valor, selecionar os processos prioritários que impactem diretamente o cliente para a $1^{\text {a }}$ fase, preferencialmente, deve conter processos de todas as diretorias;

- Mapear os processos que serão implementados nas demais fases;

- Definir como será o mapeamento dos processos;

- Definição, em conjunto com o canal da gestão da mudança, a comunicação institucional da implementação.

\section{0 - Criar comitê de desempenho e melhoria contínua}

- Definição das métricas, KPIs e metas para acompanhamento do desempenho dos processos;

- Avaliação se o desempenho dos processos está alinhado as estratégias da companhia;

- Definição do relacionamento deste comitê com conselho de BPM;

- Definição de como executar a melhoria contínua dos processos;

- Definição de como será executada a avaliação de novas oportunidades e/ou proposição de projetos.

Elaborado pelos Autores (2020).

Conforme demonstrado no plano de ação, as atividades propostas em cada etapa visam sanar o impacto das características das organizações públicas. Além disso, como a maturidade em BPM tem alto impacto na implementação do EP, algumas etapas do plano de ação visam a elevar os conhecimentos sobre BPM dentro da empresa. Nesse sentido, para a primeira etapa, os objetivos são engajar os funcionários para contribuir com a implementação do EP e apresentar os conceitos de BPM e EP. Portanto, para essa etapa, foram propostos workshops, palestras, treinamentos com avaliações, debates e possibilidades de aprendizado sobre BPM e EP por parte dos empregados.

Por consequência, a segunda etapa objetiva a criação do projeto de implementação do EP. Nessa etapa são definidos os gerentes do projeto, o sponsor, seu escopo e objetivo, além de questões como entregáveis, orçamento e equipe. Os envolvidos no projeto precisam ter conhecimento em BPM, dos processos, dos objetivos estratégicos e que possuam no mínimo dez anos de trabalho para a companhia, garantindo assim, um escopo de projeto alinhado com a estratégia a ser seguida.

Na terceira etapa, o objetivo do plano de ação é minimizar o impacto que a complexidade dos processos possa ter no desempenho das atividades executadas pela organização por meio do mapeamento do contexto da empresa. Assim, essa etapa busca alinhar o grupo do EP e colaboradores à estratégia a ser seguida pela companhia. Já a quarta etapa tem por finalidade possibilitar que o EP desempenhe suas atividades com autonomia, bem como avalie em qual o grau de maturidade em BPM a empresa se encontra, tendo em vista, que poderá haver ações sendo executas de forma isolada dentro da organização.

A quinta etapa trata da criação do canal da gestão da mudança. Nesta etapa, é muito importante criar um canal aberto de comunicação dentro da empresa, fazendo o funcionário sentir parte essencial nesse processo. Na sequência, a sexta etapa tem o objetivo de estruturar a governança em BPM na organização. Portanto, nesta etapa, alguns atores, objetivos, estruturas, serviços, relacionamentos e responsabilidades precisarão ser definidos pela organização para que a prática em BPM seja realizada na companhia.

Com objetivo de minimizar a complexidade e reduzir a burocracia, a sétima etapa proposta, prevê que sejam definidos os recursos humanos que irão compor a equipe do EP. Nesta etapa, também são definidos os recursos tecnológicos que o EP irá precisar para atuar. Já a oitava etapa prevê a capacitação mais ampla em BPM para a empresa, onde o objetivo é preparar toda a organização para a implementação do EP. Ou seja, informar como irá ocorrer a implementação e o que mudará na companhia a partir da implementação, como será a avaliação/acompanhamento do desempenho dos processos pós implementação, e criar em conjunto com o canal de gestão de mudanças a comunicação mais impactante sobre essa etapa.

A nona etapa trata especificamente sobre a implementação do EP na organização, onde o objetivo é realizar a implementação do EP após avaliação da matriz de risco e cadeia de valor, definidas na sexta etapa. Essa etapa visa a definir como ocorrerá o mapeamento dos processos na organização a partir da 
implementação do EP, se a implementação será realizada inicialmente pelo EP ou pelas áreas de negócios com apoio do EP, além de comunicar a implementação do EP para a empresa em conjunto com o canal da gestão da mudança. Por fim, a décima e última etapa proposta prevê a continuidade da organização em trabalhar com processo. Isto é proposto através de método de acompanhamento do desempenho dos processos e de ciclos de melhoria contínua.

\subsection{Avaliação do Plano de Ação Gerado}

Neste momento, visou-se avaliar o produto gerado pelo artefato (i.e., o plano de ação de implementação). Para isso, foram realizadas reuniões com os gestores da companhia aplicada a fim de verificar se as atividades propostas estavam adequadas para a implementação de um EP na organização. Inicialmente, foram realizadas reuniões individuais com os gestores e, em seguida, outra reunião com o grupo todo. Em ambas, foram demonstrados o artefato proposto e o plano de ação detalhado de cada etapa.

De posse dos dados coletados, foi avaliada a viabilidade de cada etapa nos seguintes critérios: viável, parcialmente viável ou não viável. Além disso, foram identificadas melhorias ao modelo proposto inicialmente, as quais estão apresentadas nos parágrafos a seguir.

A primeira etapa foi avaliada como parcialmente viável de aplicação na empresa. A sensibilização proposta aos gestores, foi bem recepcionada, porém realizar mini workshops com todos os funcionários da companhia foi visto como custoso e muito demorado. Dessa forma, o ideal é manter a sensibilização com os gestores e funcionários-chave. Com relação ao EAD, a opção foi bem recepcionada, mas sugeriram em formato de minivídeos informativos sobre BPM.

Para a segunda etapa, o grupo avaliou que as atividades propostas são viáveis de aplicação, sendo sugerido introduzir uma política de responsabilização por parte dos diretores pelos resultados/entregáveis. Já, na terceira e quarta etapa, todas as atividades propostas foram consideradas viáveis pelo grupo. Na quinta etapa, sugere-se envolver a área de gestão de pessoas na criação do canal de gestão da mudança e capacitar os funcionários para que desenvolvam as competências necessárias em BPM e EP.

Para a sexta etapa, avaliou-se a aplicação como viável, sugerindo-se que fosse atribuída uma atividade de criação de política de responsabilidades e resultados para os envolvidos nos processos. Para a matriz de risco, foi sugerido que os critérios para avaliação dessa matriz fossem definidos, tendo em vista que nesta etapa ainda não se teriam todos os processos mapeados. $\mathrm{Na}$ etapa sete, todas as atividades foram consideradas como viáveis e sugeriu-se envolver as áreas de apoio para a definição dos recursos propostos, como, por exemplo, envolver área de TI para definir os recursos tecnológicos.

A oitava etapa foi avaliada como viável de aplicação pelo grupo. No entanto, sugeriu-se criar algum tipo de incentivo para que as pessoas realizem o curso de capacitação de BPM e sejam valorizadas pela execução, criando uma linha de sucessão para os membros do EP. Similarmente à oitava etapa, a nona etapa também foi avaliada como vaiável. O grupo sugeriu que essa etapa deveria conter uma atividade de mapeamento inicial dos processos, definindo-se os principais processos de cada área, para posterior análise da matriz de risco possibilitando assim a priorização de quais os processos seriam implementados em primeiro momento.

Por fim, a etapa dez foi julgada como viável e foi muito bem recebida pelo grupo, salientando, inclusive, que o monitoramento e avaliação contínua dos processos servirão para avaliar o desempenho e atingimento da estratégia, bem como identificação de novas oportunidades. Sugeriu-se que fossem criados indicadores de atendimento e execução das etapas de implementação do EP na modelagem proposta.

\section{DISCUSSÃO}

Existe crescente interesse pelo aumento da produtividade e eficiência das organizações públicas, e diversos trabalhos já dispuseram esforços para analisar e propor melhorias nessas empresas (SILVA, 2014; CAMPANÁRIO et al., 2014; BANDARA et al., 2018). Compilando as respostas obtidas junto ao grupo de gestores onde $o$ artefato foi aplicado, observa-se que, praticamente, todas as atividades propostas no plano de ação são viáveis de serem aplicadas, sugerindo-se apenas alterações na execução de algumas etapas. No entanto, 
após a aplicação, algumas etapas do modelo apresentaram-se críticas e merecem um destaque, o qual é apresentado nos parágrafos abaixo.

Devido a ênfase dada pelos gestores consultados, pode-se concluir que as pessoas que trabalham na organização compõem um fator-chave para o sucesso na implementação. No entanto, dado que a forma de contratação de pessoal de organizações públicas limita a liberdade de escolha dos envolvido, é necessário utilizar o conjunto de funcionários existente para execução da tarefa, gerenciando-os adequadamente. Sendo assim, as etapas de conscientização dos envolvidos no projeto e a gestão da comunicação surgem como críticas no modelo.

Os interesses políticos envolvidos, turnover da alta gestão e a falta de visão estratégica da organização também se mostraram importantes desafios a serem superados. Para isso, recomenda-se grande atenção ao adequado planejamento do projeto, a fim de garantir a correta execução das atividades, e ao mapeamento profundo do contexto em que a empresa está inserida, de forma que as ações de implementação consigam gerenciar os riscos inerentes envolvidos. É importante ressaltar que organizações públicas são altamente impactadas pelo ambiente político, o que traz grande risco a qualquer projeto de longo prazo.

Por fim, a burocracia apresenta-se como um problema subjacente ao longo de quase todas as etapas do modelo. É bem verdade que, diferente das outras características sinalizadas, a burocracia parece afetar mais a eficiência do projeto de implementação do que sua eficácia, visto que não impede o atingimento dos objetivos do projeto, mas o torna muito mais difícil de ser alcançado. Portanto, é preciso encontrar meios de conduzir o projeto de forma a evitar os impactos das atividades burocráticas existentes. Além disso, a fim de garantir o correto funcionamento do EP após sua implementação, é fundamental que sua rotina de funcionamento seja projetada de forma enxuta.

\section{CONCLUSÃO}

O presente artigo propõe a criação de um modelo de implementação de EP para organizações públicas a fim de contemplar as características específicas deste setor. Para isso, foram cruzadas as etapas para implementação de EPs com as características de organizações públicas, ambas obtidas a partir de revisão da literatura. O modelo proposto tem como produto esperado a criação de um plano de ação para a implementação de EPs nos órgãos públicos.

Realizou-se a aplicação do modelo proposto em uma empresa pública a fim de testar sua aplicabilidade. Os resultados dessa aplicação sinalizaram que o modelo proposto é viável de ser executado, resguardadas algumas especificidades do ambiente de aplicação. Constatou-se que o diferencial da implementação de um EP em uma organização pública comparada a uma organização privada está na forma como as etapas devem ser executadas. Características específicas do setor público como estabilidade do quadro de funcionários, turnover da alta gestão, interesses políticos e burocracia geram significativos impactos na execução do modelo.

Cabe salientar que o estudo possui algumas limitações. Primeiramente, ressalta-se o fato de o artefato proposto ter sido aplicado em apenas um caso. Acredita-se que aplicações em mais organizações públicas (preferencialmente, com características distintas) poderiam gerar mais conhecimento sobre a aplicabilidade do artefato. Ressalta-se, também, que o fato de o plano de ação gerado não ter sido colocado em prática limita as percepções de qualidade do artefato obtidas a partir da aplicação.

Como pesquisas futuras, segure-se que o modelo seja aplicado em mais organizações públicas, sendo recomendada aplicação em instâncias federativas diferentes da realizada neste estudo, como órgãos municipais e federais. Além disso, se recomenda a aplicação em organizações com diferentes níveis de controle do poder público, como na administração direta (e.g. ministérios e secretarias estaduais/municiais) e em empresas públicas, dado que as influências políticas e o nível de estabilidade dos funcionários são diferentes em cada uma delas. Ademais, estudos futuros podem analisar a diferença da implementação do EP entre organizações públicas com diferentes modelos de negócios (e.g., modelos focados em produtos e modelos focados em serviços). Por fim, em todos os casos, recomenda-se que o plano de ação obtido do modelo seja aplicado a fim de se coletar mais evidências de qualidade acerca da proposta. 


\section{REFERÊNCIAS}

BANDARA, Wasana et al. Enterprise Business Process Management in the Public Sector: The Case of the Department of Human Services (DHS) Australia. Journal of Information Technology Teaching Cases, v. 8, n. 2, p. 217-231, nov. 2018. Disponível em: http://journals.sagepub.com/doi/10.1057/s41266-017-0031-5. Acesso em: 01 fev. 2020

BOER, Fernanda Gobbi de. Modelo De Estruturação De Serviços De Um Escritório De Processos Aderente Ao Grau De Maturidade Em Gestão Por Processos. 2014. 106 f. Universidade Federal do Rio Grande do Sul, 2014. Disponível em: http://hdl.handle.net/10183/109153. Acesso em: 21 dez. 2019

BOYNE, George A. Public and Private Management: What's the Difference? Journal of Management Studies, v. 39, n. 1, p. 97-122, jan. 2002. Disponível em: http://doi.wiley.com/10.1111/1467-6486.00284. Acesso em: 04 fev. 2020

CAMPANÁRIO, Milton de Abreu et al. Governança Corporativa em empresas públicas. RACE - Revista de Administração, Contabilidade e Economia, v. 13, n. 2, p. 689-718, 2014. Disponível em: http://editora.unoesc.edu.br/index.php/race/article/view/4076/xml_29. Acesso em: 10 nov. 2019

DRESCH, Aline; LACERDA, Daniel Pacheco; ANTUNES JÚNIOR, José Antonio Valle. Design Science Research: Método de Pesquisa para Avanço da Ciência e Tecnologia. [S.I.]: Bookman Editora, 2015. Disponível em: https://books.google.com.br/books?id=matYBQAAQBAJ. (Métodos de Pesquisa). Acesso em: 01 fev. 2020

DYER, Lisa et al. Front cover Creating a BPM Center of Excellence ( CoE ). [S.I.]: Redpaper, 2013. Disponível em: http://www.redbooks.ibm.com/Redbooks.nsf/RedbookAbstracts/redp4898.html?Open. Acesso em: 05 jan. 2020

ELO GROUP. Roadmap para Implantação de um Escritório de Processos: Promovendo a inovação organizacional e a governança de BPM. . [S.I.]: ELO Group. , 2008 Acesso em: 11 jan. 2020

FELIX, Rozelito; FELIX, Patrícia do Prado; TIMÓTEO, Rafael. Balanced Scorecard: adequação para a gestão estratégica nas organizações públicas. Revista do Serviço Público, v. 62, n. 1, p. 51-74, 2011. Acesso em: 22 fev. 2020

GESPÚBLICA. INSTRUMENTO DE AUTOAVALIAÇÃO DA GESTÃO PÚBLICA - IAGP 250 Pontos. . [S.I: s.n.], 2010. Acesso em: 15 jan. 2020

HEVNER, Alan R.; MARCH, Salvatores T.; PARK, Jinsoo. Design Science in Information Systems Research. MIS Quartely, v. 28, n. 1, p. 75-105, jun. 2004. Disponível em: http://link.springer.com/10.1007/BF01205282 Acesso em: 14 fev. 2020

HOLMSTRÖM, Jan; KETOKIVI, Mikko; HAMERI, Ari-Pekka. Bridging Practice and Theory: A Design Science Approach. Decision Sciences, v. 40, n. 1, p. 65-87, fev. 2009. Disponível em: http://doi.wiley.com/10.1111/j.1540-5915.2008.00221.x. Acesso em: 12 jan. 2020

JESUS, Leandro et al. A Framework for a BPM Center of Excellence. Business Process Trends. [S.I: s.n.]. Disponível em: http://www.bptrends.com/publicationfiles/FOUR 09-09-ART-Framework for BPM Ctr Excellence-Jesus et al.pdf. , 2009 Acesso em: 10 out. 2019

JESUS, Leandro et al. Estudo de Caso sobre uma Empresa Brasileira. In: BROCKE, James vom; ROSEMANN, Michael (Org.). . Man. BPM Gestão Process. Negócio. Porto Alegre: Bookman, 2015. p. 399-420. Acesso em: 25 fev. 2020

NQAMPOYI, Vuvu; SEYMOUR, Lisa F.; LAAR, David Sanka. Effective Business Process Management Centres of Excellence. In: TJOA, A.M. et al. (Org.). . Lect. Notes Bus. Inf. Process. Poznan: Springer, 2016. v. 268. p. 207222. Disponível em: http://link.springer.com/10.1007/978-3-319-49944-4_16. Acesso em: 01 fev. 2020 
OLIVEIRA, Joyce Aline Pereira. Fatores Envolvidos na Estruturação de um Escritório de Processos em uma Organização Pública: Uma Pesquisa-Ação. 2014. 142 f. Universidade Federal do Pernambuco, 2014. Acesso em: 28 jan. 2020

PAIM, Rafael; MANSUR CAULLIRAUX, Heitor; CARDOSO, Rodolfo. Process management tasks: a conceptual and practical view. Business Process Management Journal, v. 14, n. 5, p. 694-723, 12 set. 2008. Disponível em: https://www.emerald.com/insight/content/doi/10.1108/14637150810903066/full/html. Acesso em: 09 jan. 2020

PINHO, Bruno et al. Estruturação de Escritório de Processos Projeto de Pesquisa Grupos de Pesquisa Participantes. . Rio de Janeiro: [s.n.], 2008. Acesso em: 18 jan. 2020

PORTER, Michael E. Competitive strategy: Techniques for Analyzing Industries and Competitors. Nova Iorque: The Free Press, 1980. Acesso em: 14 fev. 2020

RICHARDSON, Clay. Process Governance Best Practices : Building a BPM Center of Excellence. Business Process Trends. [S.I: s.n.]. , 2006 Acesso em: 01 fev. 2020

ROSEMANN, Michael. The Service Portfolio of a BPM Center of Excellence. Business Process Trends. [S.I: S.n.]. , 2008 Acesso em: 05 jan. 2020

SCHEER, August-Wilhelm; HOFFMANN, Michael. The Process of Business Process Management. In: VOM BROCKE, Jan; ROSEMANN, Michael (Org.). . Handb. Bus. Process Manag. 2. Berlin, Heidelberg: Springer Berlin Heidelberg, 2015. p. 1-865. Disponível em: http://link.springer.com/10.1007/978-3-642-45103-4. Acesso em: 08 jan. 2020

SILVA, Jorge Gonçalves. Gestão por Processos em Organizações Públicas: Uma análise sobre obstrutores e facilitadores do Mapeamento de Processo em Organizações Públicas. 2014. 90 f. Fundação Getúlio Vargas, 2014. Acesso em: 21 jan. 2020

TREGEAR, Roger; JESUS, Leandro. Estabelecendo o Escritório de Processos. Rio de Janeiro: ELO Group, 2008. Acesso em: 22 fev. 2020

TREGEAR, Roger; JENKINS, Teri. Government Process Management : A review of key differences between the public and private sectors and their influence on the achievement of public sector process management . Business Process Trends. [S.I: s.n.]., 2007 Acesso em: 11 jan. 2020

USIRONO, Carlos Hiroshi. Escritório de Processos. BPMO (Business Process Management Office). [S.I.]: Brasport, 2015. Acesso em: 05 jan. 2020 